\title{
Male reproductive organs of Apis dorsata
}

\author{
G Koeniger 1, M Mardan 2, F Ruttner 1 \\ 1 Institut für Bienenkunde (Polytechnische Gesellschaft), Fachbereich Biologie der JW Goethe- \\ Universität Frankfurt, Karl-von-Frisch-Weg 2, D-6370 Oberursel, FRG \\ 2 Universiti Pertanian Malaysia, Department of Plant Protection, \\ 43400 Serdang, Selangor, Malaysia
}

(Received 20 February 1990, accepted 6 March 1990)

\begin{abstract}
Summary - Based on an examination of a large number of everted copulatory organs of Apis dorsata drones, a new description of the structure is given (fig 1c), which differs from previous publications. The result is of significance for classification within the genus Apis.
\end{abstract}

Apis dorsata / Apis laboriosa / endophallus / classification

\section{INTRODUCTION}

The endophallus is a reliable character for separating the species. In 6 species, Apis andreniformis, Apis florea, Apis koschevnikovi, Apis cerana, Apis mellifera and Apis dorsata, the endophallus is clearly different (Simpson, 1960, 1970; Ruttner, 1988; Tingek et al, 1988; Wongsiri et al, 1990). Whether Apis dorsata and Apis laboriosa display sufficient differences to be considered as distinct species is still controversial. McEvoy and Underwood (1988) stated that they could not find diagnostic differences at the endophallus in their samples of Apis laboriosa and Apis dorsata; this is an important argument for classifying both types under one species.
However, the published drawings of the endophallus of Apis dorsata (Simpson, 1970) and Apis laboriosa (McEvoy and Underwood, 1988) show distinct differences (figs 1A and B). Simpson (1970) describes 3 dorsal cornua and 1 ventral cornu, while McEvoy and Underwood (1988) separate the cornua into 2 median and 2 lateral cornua. For comparison, we numbered the cornua from 1-4. In figure 1A, cornu 1 has an additional small bump; the 2nd has a flat step after which the cornu narrows. The 3rd and 4th cornua are about the same length in $A$, while in $B$, cornu 4 is distinctly shorter than 3 . In addition, the fimbriate lobe is different in shape.

To clarify the above contradictory findings, in the present study, drones of Apis dorsata from Malaysia were collected and examined. 


\section{MATERIAL AND METHODS}

More than 50 Apis dorsata drones were collected in February 1988 and 25 drones from another colony were collected in July 1989. Both colonies were located at the university campus in Selangor. The eversion of the endophallus was induced by manual compression of thorax and abdomen, as described for sperm collection in Apis mellifera. Different stages of eversion were conserved in $70 \%$ ethanol. This reduced the sticky character of the cornual secretion and the cornua swam freely in the alcohol. At the same time, the inner pressure of the endophallus was reduced; thus, the position of the cornua may have differed from that in fresh material.

\section{RESULTS}

Drawing $\mathrm{C}$ depicts different endophalli. We diagnosed incomplete eversion for structures which had an orifice at the end. Then, the uneverted part could often be recognized through the chitinous membrane. In particular, the eversion of the fimbriate lobe was only completed by 1 of our 75 drones.

In our samples, cornu 1 had a distinct hump at its base. Cornu 2 showed either a flat step, as shown in figure $1 \mathrm{~A}$, or had (14 samples) an additional horn (cornu 2a), originating at the flat step. Cornua 1 and 2 had a common origin. These dorsal appendages thus formed 3 cornua in all: 1,2 and $2 a$.

Cornua 3 and 4 had a common origin. Their length was about the same. The volume appeared different in different samples, presumably because of dehydratation by ethanol.

The fimbriate lobe of 1 sample was larger than in figure 1A, but the shape seemed similar; the 2 distal lobes being larger than the proximal ones. Only the split between the distal lobes was much longer.
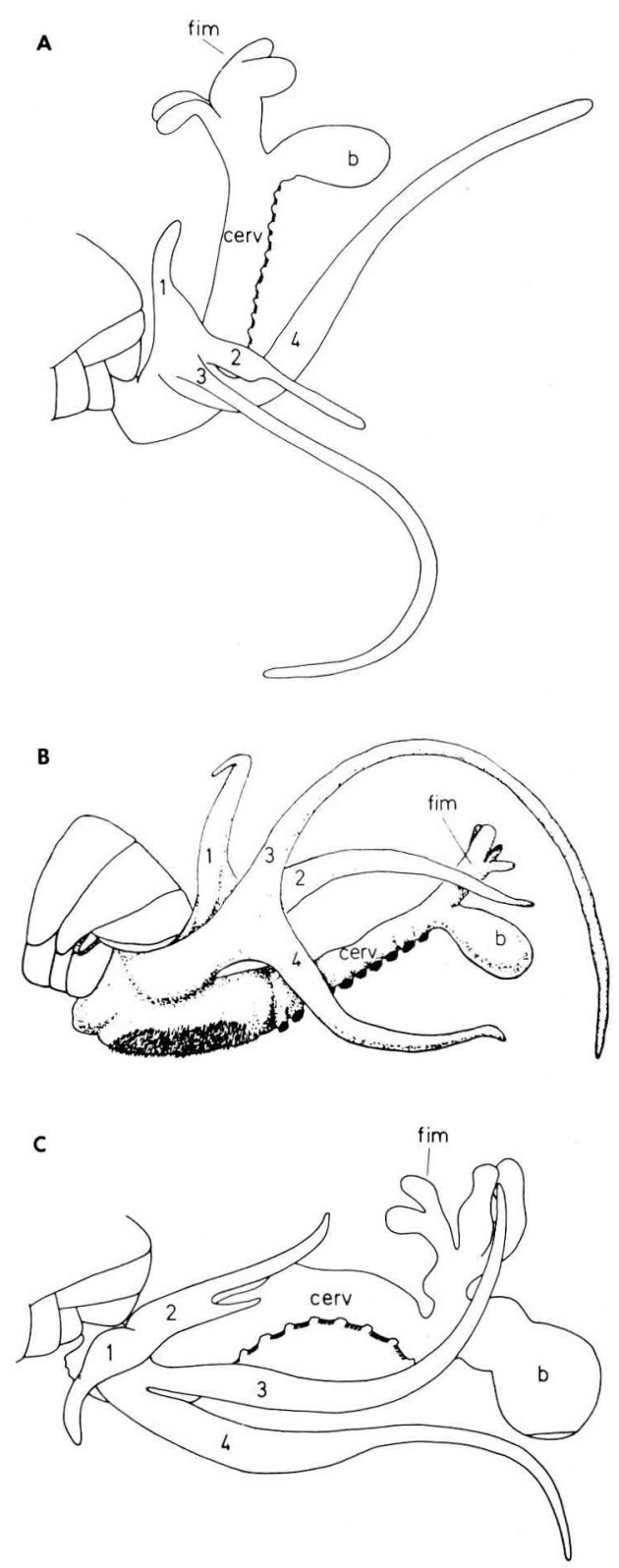

Fig 1. Everted endophalli of Apis dorsata: A: after Simpson (1970); B: after McEvoy and Underwood (1988); C: own results; b: bulbus; cerv: cervix; fim: fimbriate lobe; 1 and 2: dorsal cornua; 3 and 4: ventral cornua. 
The bulb might not have been fully everted because, even at the stage in figure $C$, there was a large orifice at the end.

\section{DISCUSSION}

The endophalli of Apis dorsata in our samples show similar structures to those in the drawing of Simpson (1970): a) the bump at the base of cornu 1 ; b) cornu 2 has a flat step, either with an orifice, or with another small everted cornu (2a); c) the length of cornua 3 and 4 are the same; d) the shape of the fimbriate lobe is similar.

The different position of cornu 4 in A and $C$ seems to be induced by the sticky cornual secretion which often influences the position of the cornua. Even after being in $70 \%$ ethanol the cornua still stuck together and had to be separated very carefully for study. Thus, we do not interpret cornu 4 in figure $1 \mathrm{~A}$ as a dorsal horn, but as a ventral appendage which has been artificially bent upwards.

Cornua 1, 2 and 2a have a common origin and can be considered as the dorsal cornua. Cornua 3 and 4 again have the same origin and can be considered as ventral cornua. This corresponds to the medium and lateral cornua of McEvoy and Underwood (1988).

Comparison of figure $\mathrm{A}, \mathrm{B}$ and $\mathrm{C}$ reveals that 3 different illustrations are given for the endophallus of the same species. Fig $1 \mathrm{~A}$ is based on a single everted specimen; the differences may easily be explained by difficulties in preparation given the long thin sticky cornua. As far as fig $1 B$ is concerned, McEvoy and Underwood (1988) state explicitly that they did not find distinct differences between their samples of Apis dorsata and Apis laboriosa. This divergence of their illustration with our own results regarding Apis dorsata is a consideration which requires a thorough re-examination of the everted endophallus of Apis laboriosa.

Résumé - Organes reproducteurs d'Apis dorsata. Les auteurs présentent une nouvelle description basée sur l'examen minutieux d'un grand nombre d'organes copulateurs éversés de mâles d'Apis dorsata. Cette description est différente de celles précédemment publiées et présente un intérêt pour la taxonomie du genre Apis.

\section{Apis dorsata / Apis laboriosa / endo- phallus / taxonomie}

\section{Zusammenfassung - Männliche Geschlechtsorgane von Apis dorsata. Eine genaue Untersuchung einer großen Anzahl von evertierten Begattungsorganen von Apis dorsata ergab eine neue Beschreibung der Strukturen (Abb 1C) im Vergleich zu früheren Zeichnungen ( $A b b \mathrm{~A}$ und $B$ ). Diese Unterschiede sind für die Klassifizierung innerhalb der Gattung Apis von Bedeutung.}

\section{Apis dorsata / Apis laboriosa / Endo- phallus / Klassifizierung}

\section{REFERENCES}

McEvoy M, Underwood BA (1988) The drone and species status of the Himalayan honey bee, Apis laboriosa (Hymenoptera: Apidae). $J$ Kans Entomol Soc 61, 246-249

Ruttner F (1988) Biogeography and Taxonomy of Honeybees. Springer Verlag, Berlin

Simpson H (1960) Male genitalia of Apis species. Nature 185, 56

Simpson $H$ (1970) The male genitalia of Apis dorsata L (Hym: Apidae). Proc R Entomol Soc Lond A 45, 169-171 
Tingek S, Mardan M, Rinderer TE, Koeniger N, Koeniger G (1988) Rediscovery of Apis vechti (Maa, 1953): the Saban honeybee. Apidologie 19, 97-102

Wongsiri $S$, Limbipichai $K$, Tangkanasing $P$, Mardan $M$, Rinderer TE, Sylvester HA,
Koeniger G, Otis G (1990) Evidence of reproductive isolation confirms that Apis andreniformis (Smith, 1858) is a separate species from sympatric Apis florea (Fabricius, 1787). Apidologie 21, 47-52 